\title{
A different technique in gasless, laparoendoscopic, single-site myomectomy
}

\author{
Guixiu Jin ${ }^{1,2} \cdot$ Xiumin Zhao ${ }^{1} \cdot$ Danyang Zhu ${ }^{1}$
}

Received: 26 November 2019 / Accepted: 22 September 2020 / Published online: 14 December 2020

(c) The Author(s) 2020

\begin{abstract}
Background The aim of this study was to introduce a novel technique for gasless, laparoendoscopic, single-site (GLESS) myomectomy and to evaluate its feasibility and safety.

Methods A retrospective observational study was performed at a hospital from Sep 2017 to Nov 2018. 15 patients with symptomatic subserosal or intramural myomas underwent GLESS myomectomy.

Results The mean age and body mass index were $41.73 \pm 8.58$ years and $22.72 \pm 2.27 \mathrm{~kg} / \mathrm{m}^{2}$, respectively. 5 patients had a history of abdominal surgery, including four caesarean deliveries and one myomectomy. The mean operative duration, blood loss volume, time to specimen removal, time of bowel activity and postoperative hospitalization duration were $156.47 \pm 62.19 \mathrm{~min}$, $57.33 \pm 72.35 \mathrm{ml}, 29.87 \pm 13.6 \mathrm{~min}, 27.67 \pm 10.06 \mathrm{~h}$, and $3.4 \pm 0.74$ days, respectively. The operation was successful in all patients, there were no surgical or wound complications in any patient, and the histopathological result was leiomyoma in all 15 patients.
\end{abstract}

Conclusion The procedure is feasible and safe in selected patients with symptomatic myomas.

Keywords Myomectomy $\cdot$ Gasless $\cdot$ Laparoendoscopic $\cdot$ Single-site

Uterine myomas are the most frequent benign uterine tumours in reproductive-aged women. Surgery is performed in women with menorrhagia, dysmenorrhea, pelvic pain and enlarged uterine fibroids [1]. With the development of laparoscopic techniques, single-port, laparoscopic myomectomy is currently performed as a minimally invasive surgical technique, which offers the advantages of a more cosmetic result, reduced pain, faster recovery, fewer adhesions and reduced blood loss. However, traditional laparoscopic surgery has numerous adverse effects on cardiopulmonary function due to

Guixiu Jin and Xiumin Zhao have contributed equally to this work.

Supplementary Information The online version contains supplementary material available at https://doi.org/10.1007/s0046 4-020-08044-y.

Danyang Zhu

zdy508@163.com

1 Department of Gynaecology and Obstetrics, The First People's Hospital of Taizhou, Hengjie Road 218, Taizhou 318020, Zhejiang, China

2 Department of Gynecology and Obstetrics, Taixing People's Hospital, Taixing, Jiangsu, China carbon dioxide pneumoperitoneum [2]. This shortcoming can be avoided using the gasless laparoscopic technique. Gasless laparoscopy can be used in the treatment of benign and malignant gynaecological diseases; in recent years, various surgical instruments and techniques have been used in these procedures [2-6]. The main disadvantages of gasless, laparoendoscopic, single-site (GLESS) surgery are the inline viewing and limited area, which increase the frequency of collisions of laparoscopic instruments extra- and intracorporeally. Therefore, we designed an operation platform to establish a good view in GLESS surgery using an abdominal wall lift system and an umbilical fixation system. This report aims to assess the feasibility and safety of a novel, gasless, single-incision, abdominal access technique for laparoscopic myomectomy.

\section{Materials and methods}

\section{Clinical data}

15 patients who underwent GLESS myomectomy from Sep 2017 to Nov 2018 at The First People's Hospital of Taizhou, Zhejiang, China, were evaluated in this study. A 
specific informed consent form was signed by all patients, and the study was approved by the institutional review board of The First People's Hospital of Taizhou, Zhejiang, China. All operations were performed by a single surgeon.

The surgical indications were as follows: patients were diagnosed by ultrasonography with symptomatic uterine myoma including menstrual disorders, dysmenorrhea, and infertility or increasing myoma size after follow-up; no other comorbidities were present; uterine preservation was required; fibroid position, size and number were determined by vaginal ultrasound before surgery; cervical or endometrial lesions were excluded. The following demographic characteristics of the patients were collected: age, body mass index (BMI), history of abdominal surgery, location of the myoma, and size and number of myoma(s). The operative duration, estimated blood loss volume, complications, time to specimen removal, pathological results, postoperative hospitalization duration and postoperative visual analogical scale (VAS) pain score were recorded and analysed. The duration of the operation was defined as the period from skin incision to closure, the return of bowel activity as the period from the end of anaesthesia to the first occurrence of bowel gas passage. The degree of postoperative pain was assessed using a VAS at $1 \mathrm{~h}, 6 \mathrm{~h}$ and $24 \mathrm{~h}$ postoperatively.

\section{Surgical access platform and instruments}

We used an abdominal wall lift system as the method of exposure and a home-made umbilical fixation system as the access device in the GLESS procedure. The abdominal wall lift system (Patent: CN208958194U, CN208958195U) was adopted as the method of exposure in the GLESS procedure (Fig. 1A). The lifting system is composed of a suspension rod, a triangular device and two abdominal wall lifting clamps. The triangular device is used for connecting the tail of the suspension rod and the lifting clamps. The head end of the suspension rod is connected to the umbilical fixation system. The suspension rods are assembled using horizontal and vertical suspension rods to adjust height and width.

The umbilical fixation (Fig. 1C) device is composed of a stalked perforated steel plate and a hook. The perforated steel plate has a fixator on both sides, which pulls the skin around the umbilicus and serves to fix the umbilicus. The umbilical fixation system can rotate the skin of the umbilicus wound locally in any direction so that the incision plane faces the lesion, and the incision space is completely converted into an operative space, thereby improving the operative efficiency.

Surgical instruments: we designed some special laparoscopic instruments, such as bent separation forceps and

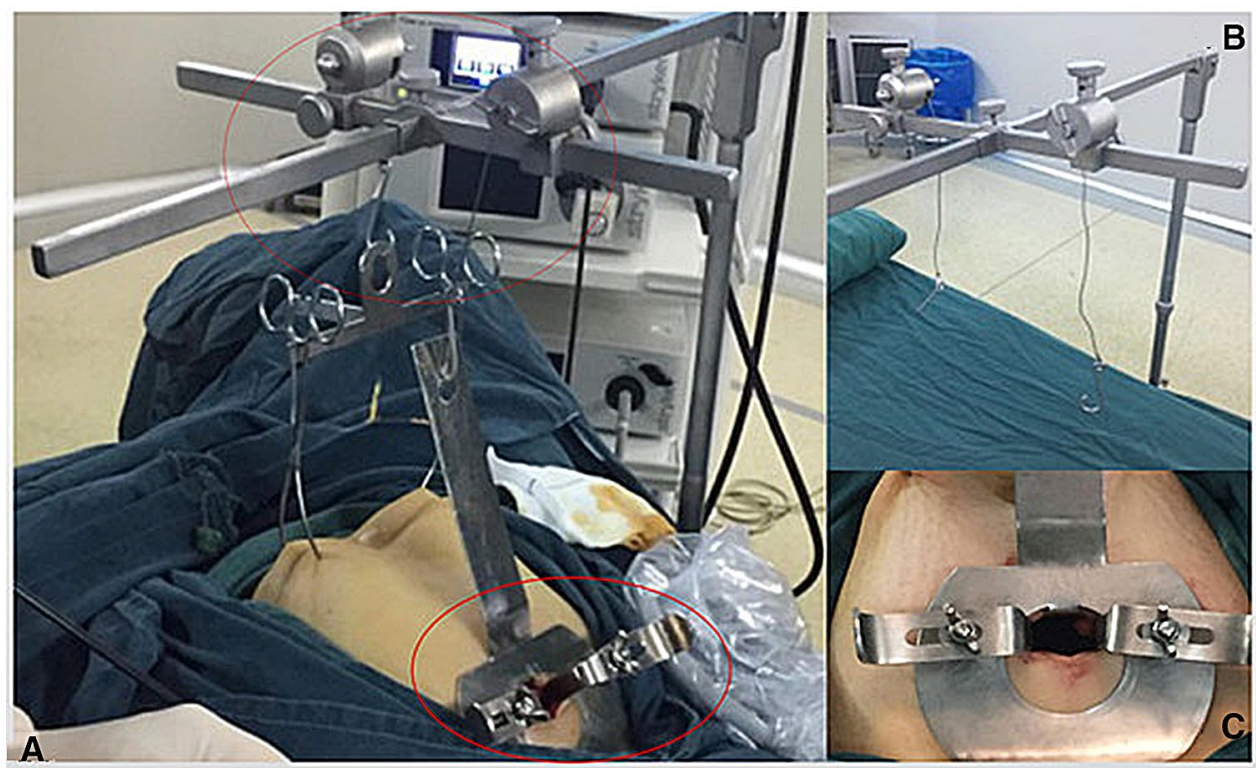

Fig. 1 The abdominal wall lifting system and umbilical fixation device. The lifting system (as the red dotted line showed) is composed of a suspension rod, a triangular device and two abdominal wall lifting clamps. The triangular device is used for connecting the tail of the suspension rod and the lifting clamps. The head end of the suspension rod is connected to the umbilical fixation system. The suspension rods are assembled using horizontal and vertical suspension rods to adjust height and width (B). The umbilical fixation device (as the red solid line showed) is composed of a stalked perforated steel plate and a hook. The perforated steel plate has a fixator on both sides, which pulls the skin around the umbilicus and serves to fix the umbilicus. The umbilical fixation system can rotate the skin of the umbilicus wound locally in any direction so that the incision plane faces the lesion, and the incision space is completely converted into an operative space, thereby improving the operative efficiency $(\mathbf{C})$ 
myoma-grasping forceps, with a unique bent design to effectively reduce the interference between instruments during the operation. The myoma-grasping forceps have a thicker head and a thinner handle (Fig. 2, Patent: CN208958196U). Compared with ordinary 5-mm grasping forceps, the designed forceps can effectively increase the occlusal area and accurately grasp fibroids.

\section{Surgical procedure}

General anaesthesia was established with the patient in a dorsal lithotomy position on the operating table. A 2-2.5$\mathrm{cm}$ incision was made vertically in the umbilicus to enter the abdominal cavity. Then, the umbilical fixation device was placed in position to be fixed to the abdominal wall, and the lifting system was used to lift the abdominal wall. The lifting system was applied using a cloth towel clamp and lifting the subcutaneous tissue on both sides of the lower abdomen. In this way, the small vertical incision becomes a wider opening and provides an easy orifice for the entry of the laparoscope and the laparoscopic instruments, all of which were reusable.

To reduce haemorrhage in the myoma, $10 \mathrm{IU} / 100 \mathrm{ml}$ of vasopressin in normal saline was injected into the cervix before myoma removal. All visible myomas were removed. Whilst we used straight instruments, most were customdesigned, bent instruments. The overall procedure for GLESS myomectomy was performed similarly to that for conventional laparoendoscopic single-site surgery (LESS) myomectomy with pneumoperitoneum. However, the extraction of specimens was different from that in the traditional technique. In this study, small myomas were removed directly through the umbilical foramen, whilst large myomas were extracted after being cut into smaller pieces with a knife in the sample bag through the umbilicus, similar to peeling apples; a morcellator was not used.

\section{Statistical analysis}

SPSS version 18.0 (SPSS, Inc., Chicago, IL) was used for statistical analysis. Data are expressed as the mean \pm SD (range) for continuous variable and the frequency (percentage) for categorical variables.

\section{Results}

All the procedures were performed successfully using our technique. A uterine manipulator was used in three procedures. The demographic characteristics of the patients

Table 1 Demographic characteristics of the patients

\begin{tabular}{lll}
\hline $\begin{array}{l}\text { Demographic charac- } \\
\text { teristics }\end{array}$ & Mean \pm SD & Range \\
\hline Age (years) & $41.27 \pm 8.58$ & $26-52$ \\
BMI $\left(\mathrm{kg} / \mathrm{m}^{2}\right)$ & $22.72 \pm 2.27$ & $19.62-25.96$ \\
Abdominal & Caesarean section (4) & \\
Surgery history & Myomectomy (1) & \\
Myoma type & \\
Intramural & 3 \\
Subserosal & 2 \\
Submucosal & 0 \\
Combined & 10 & \\
\hline
\end{tabular}

Fig. 2 Bent separation forceps (A) and myoma-grasping forceps (B). Unique bent design for separation forceps to effectively reduce the interference between instruments during the operation (A). The myoma-grasping forcep (B) shave a thicker head and a thinner handle. Compared with ordinary 5-mm grasping forceps, the designed forcepscan effectively increase the occlusal area and accurately grasp fibroids

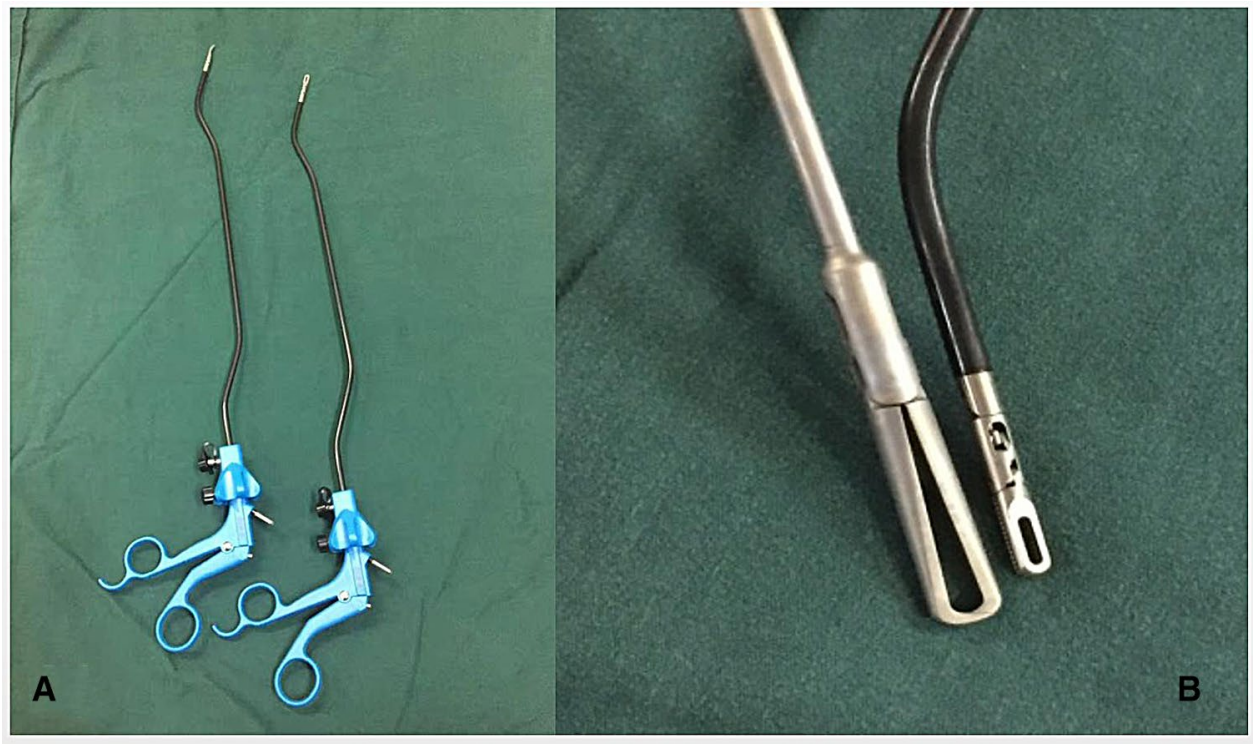


are shown in Table 1. The mean age of the patients was $41.27 \pm 8.58$. The mean BMI was $22.72 \pm 2.27 \mathrm{~kg} / \mathrm{m}^{2} .5$ patients had a history of previous abdominal surgery: one had a traditional myomectomy, and the remaining four had one caesarean delivery each. The operative findings of the patients are shown in Table 2. The average myoma size $5.79 \pm 3.12 \mathrm{~cm}$, and the mean number of myomas removed was $3.87 \pm 6.02$ (range, 1-25), excluding those smaller than $1 \mathrm{~cm}$. The average blood loss volume was $57.33 \pm 72.35 \mathrm{ml}$. The largest number of myomas was 25 , the longest operative duration was $280 \mathrm{~min}$, and the most blood loss volume was $300 \mathrm{ml}$. None of the patients were treated with blood transfusions. The mean operative duration was $156.47 \pm 62.19 \mathrm{~min}$, and the average time of bowel activity was $27.67 \pm 10.06 \mathrm{~h}$. The postoperative hospitalization duration was $3.4 \pm 0.74$ days. The postoperative VAS pain score after 1,6 , and $24 \mathrm{~h}$ was $2.07 \pm 0.26,2.07 \pm 0.59$ and $1.87 \pm 1.36$, respectively. Three patients used analgesic drugs after the operation.

There were no surgical or wound complications in any patient, and the histopathological result was leiomyoma in all cases.

\section{Discussion}

The present study demonstrates that GLESS myomectomy with our technique is a safe and effective alternative to conventional laparoscopic myomectomy. It is very low in cost

Table 2 Operative findings of the patients

\begin{tabular}{lll}
\hline Clinical outcome & Mean +SD & Range \\
\hline No. of myomas resected by myomectomy & $3.87 \pm 6.02$ & $1-25$ \\
Size of myoma (cm) & $5.79 \pm 3.12$ & $1-11$ \\
Adhesion & & \\
Yes & $3(20 \%)$ & \\
No & $12(80 \%)$ & \\
Blood loss (ml) & $57.33 \pm 72.35$ & $20-300$ \\
Duration of operation (min) & $156.47 \pm 62.19$ & $45-280$ \\
Removing specimen time (min) & $29.87 \pm 13.60$ & $12-58$ \\
Time of bowel activity (h) & $27.67 \pm 10.06$ & $17-46$ \\
Postoperative hospital time (day) & $3.4 \pm 0.74$ & $3-5$ \\
VAS score for pain & & \\
1st hour & $2.07 \pm 0.26$ & $2-3$ \\
6th hour & $2.07 \pm 0.59$ & $1-4$ \\
24th hour & $1.87 \pm 1.36$ & $1-5$ \\
Analgesic drugs using & & \\
Yes & $3(20 \%)$ & \\
No & $12(80 \%)$ & \\
\hline
\end{tabular}

compared to the use of trocars in conventional multiport laparoscopy or other gasless, laparoscopic techniques. In addition, the tools are reusable after sterilization and disinfection and could easily be promoted. Since the late 1980s, laparoscopic technology, with a laparoscope, $\mathrm{CO}_{2}$ gas and several trocar ports as the main elements, has developed rapidly because of the reduced pain, faster recovery and more cosmetic incision. The desire to develop more minimally invasive surgical techniques has led to a transition from multiple-port surgery to port-less or single-port surgery, known as natural orifice transluminal endoscopic surgery (NOTES) and LESS techniques. In traditional laparoscopic surgery, the pressure of $\mathrm{CO}_{2}$ is used to push away the surrounding tissues in the body cavity and provide a satisfactory surgical space. However, $\mathrm{CO}_{2}$ can enter the circulatory system through the peritoneum, abdominal organs and broken vessels, resulting in adverse effects on the circulatory system, the respiratory system, and the nervous system, as well as leading to postoperative shoulder pain, nausea and vomiting [7]. Therefore, an increasing number of surgeons are focusing on gasless laparoendoscopic surgery to avoid the detrimental effects of pneumoperitoneum in high-risk patients who have cardiopulmonary or metabolic disorders, and high American Society of Anesthesiologist (ASA) status $(\geq$ II) $[8,9]$. In recent years, GLESS has been reported in the treatment of various gynaecologic diseases, including in hysterectomy and adnexal surgery [5, 6, 10-12]. However, GLESS is not widely performed for other gynaecologic conditions because it requires much suturing and knot tying. The major drawback to LESS or GLESS is the frequent collisions of laparoscopic instruments extra- and intracorporeally, ascribed to the lack of triangulation and the limited operating area. Advances in technology have led to the development of special access devices and instruments, providing potential solutions to these problems. Using conventional, rigid, straight instruments, it is difficult to roll threads around an instrument with another instrument to tie intracorporeal knots because these instruments are nearly parallel in single-port laparoscopic surgery.

Single-port laparoscopic myomectomy (SP-LM) is difficult to apply because it is inevitably accompanied by technical difficulties, particularly in suturing and knotting. In our study, there was no need to establish a pneumoperitoneum, and a small incision of $2.5 \mathrm{~cm}$ was made in the umbilicus to facilitate the suture needle entering, leaving, suturing and knotting which can be performed with a common long-handle needle holder, with a method similar to that applied in conventional laparoscopic surgery (Fig. 3). Choi et al. did continuous suturing tied with a Hem-o-lok clip or suturing by barbed suture to overcome the limitations [13]. By our surgical access platform and instruments, 


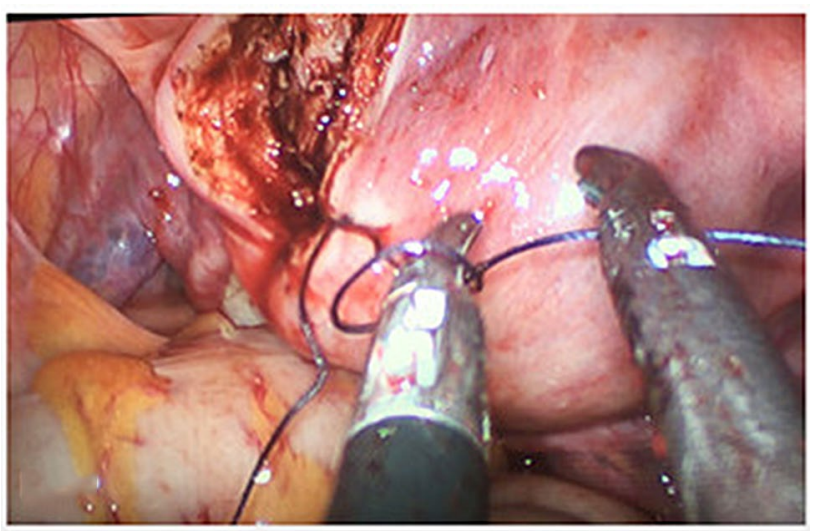

Fig. 3 Suturing knot. Suturing knot in the abdominal cavity with no colliding between the instruments

we can easily complete the continuous suturing by pulling the suture extracorporeal which can maintain the tension without instruments collisions, shorten the operation time and reduce bleeding (as shown in the supplementary surgery video). Nearly $30 \%$ of patients still need an additional hole to complete the operation as knotting is another difficulty in surgery [14]. Some researchers proposed perform single-port surgery by suturing with robotic surgery, which undoubtedly increase the cost of surgery [15]. Single-port laparoscopically assisted-transumbilical ultraminilaparotomic myomectomy (SPLA-TUM) is another way to reduce the surgery difficult, but it was unsuitable for fibroid which located on the lower posterior wall of the uterus or lateral pelvic wall [16]. In addition, an enlarged umbilical incision may increase the incidence of hernias. Our study showed that GLESS can easily tie a knot extracorporeal, which undoubtedly greatly reduces the difficulty of surgery (as shown in the Online video). We can also easily place gauze though umbilical holder to improve the surgical field of vision which is not possible with traditional gas less laparoscopy.

In our study, we used a gasless, single-port system created with an abdominal wall lifting system and an umbilical fixation system that made transumbilical myoma extraction possible. The umbilical fixation system widens the umbilical incision, and the lifting system completely converts the incision space into the operative space, thereby improving the operative efficiency. In addition, we have designed some special laparoscopic instruments, such as bent separation forceps and myoma-grasping forceps. The unique bent design is useful in preventing crowding and making more room for triangulation.

Although minimally invasive laparoscopic surgery has many advantages when compared to traditional surgery, some difficulty remains in removing large tissue specimens through small incisions. To achieve this, morcellation using either a mechanical power morcellator or a surgical scalpel in the peritoneal cavity should be considered [17]. However, power morcellation-related complications, such as injury to blood vessels and adjacent organs, can occur [18]. This method also carries the risk of unintentional dissemination of the removed tissue in the open peritoneal cavity, which could lead to the recurrence of benign tumours, and even more worrying, the spread of malignant tumours, such as uterine sarcoma, which may cause a decrease in overall survival [19, 20]. In April 2014, the U.S. Food and Drug Administration issued a safety communication warning that power morcellation should not be used due to the risk of intraperitoneal malignant tumour dissemination during laparoscopic surgery [21].

Our homemade, single-port device can be used to easily remove specimens. Small myoma specimens less than $2 \mathrm{~cm}$ can be removed directly to avoid omission. Larger myomas can be placed into a sample bag and then removed through the umbilical incision after being cut into small pieces, similar to peeling an apple, to avoid the risk of myoma dissemination under laparoscopy (Fig. 4). In addition, the abdominal lifting system used two lifting clamps to grasp the abdominal wall tissue, avoiding the vascular injury caused by Kirschner wires passing through the subcutaneous tissue of the abdomen.

Although the technique has some advantages, it also has some shortcomings, including a longer operative duration and the use of specialized instruments. Intracorporeal suturing is a significant component of laparoscopic myomectomy and presents an even greater challenge in GLESS surgery; thus, there is a learning curve involved in mastering this technology. Whilst it is difficult to lift the anterior abdominal wall mechanically in obese patients, the abdominal wall can easily be lifted in normal- or low-weight patients. In our study, the patients' BMI ranged from 19.62 to 25.96. The present study is a pilot study with a small sample and no controls. Prospective controlled studies are needed to determine the safety, advantages and disadvantages of this technique.

\section{Conclusion}

The current study demonstrates that our new technique overcomes many disadvantages of the conventional laparoendoscopic single-site myomectomy technique; it is safe, feasible and inexpensive. However, it represents only the retrospective results of a limited number of cases, and further studies with adequate samples are needed to illustrate its long-term safety. 
Fig. 4 Large myomas removement. Large myomas were put into the sample bag and removed from the umbilical incision by cutting the tissues into small pieces just like peeling an apple

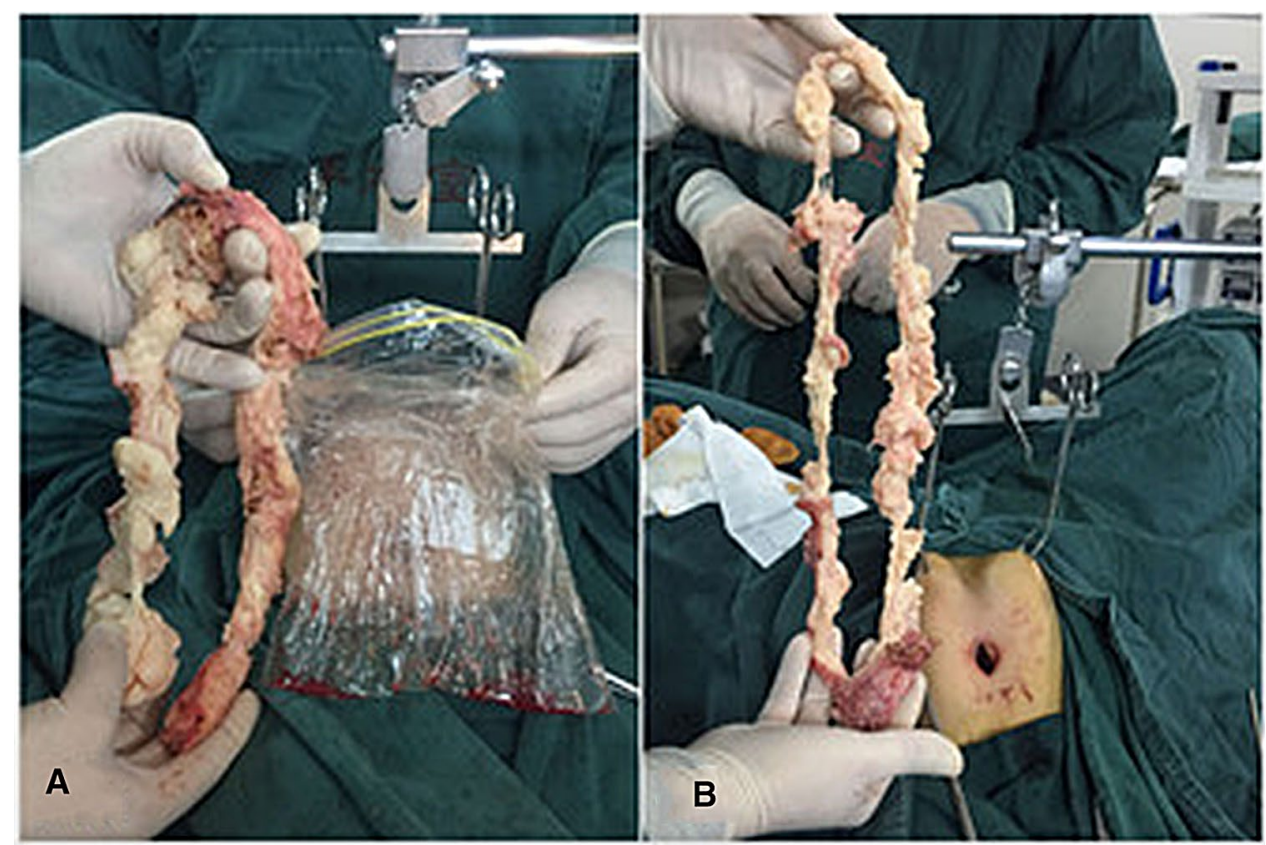

Acknowledgements This work was supported by the Zhejiang Public Welfare Programme Technology Application Research Project (Grant Number LGF18H040002). The funders played no role in the study design, data collection and analysis, decision to publish, or preparation of the manuscript.

\section{Compliance with ethical standards}

Disclosures Authors Guixiu Jin, Xiumin Zhao and Danyang Zhu have no conflicts of interest or financial ties to disclose.

Open Access This article is licensed under a Creative Commons Attribution 4.0 International License, which permits use, sharing, adaptation, distribution and reproduction in any medium or format, as long as you give appropriate credit to the original author(s) and the source, provide a link to the Creative Commons licence, and indicate if changes were made. The images or other third party material in this article are included in the article's Creative Commons licence, unless indicated otherwise in a credit line to the material. If material is not included in the article's Creative Commons licence and your intended use is not permitted by statutory regulation or exceeds the permitted use, you will need to obtain permission directly from the copyright holder. To view a copy of this licence, visit http://creativecommons .org/licenses/by/4.0/.

\section{References}

1. Buttram VC Jr, Reiter RC (1981) Uterine leiomyomata: etiology, symptomatology, and management. FertilSteril 36:433-445

2. TekeliogluUY EA, Demirhan A, Akkaya A, Ozturk S, Bilgi B (2013) The prolonged effect of pneumoperitoneum on cardiac auto- nomic functions during laparoscopic surgery; are we aware? Eur Rev Med Pharmacol Sci 17:895-902

3. Akira S, Abe T, Igarashi K, Nishi Y, Kurose K, Watanabe M (2005) Gasless laparoscopic surgery using a new intra-abdominal fan retractor system: an experience of 500 cases. J Nippon Med Sch 72:213-216

4. Palomba S, Zupi E, Falbo A, Russo T, Marconi D, Zullo F (2010) New tool (Laparotenser) for gasless laparoscopic myomectomy: a multicenter- controlled study. Fertil Steril 94:1090-1096

5. Ulker K, Huseyinoglu U, K, (2013) Management of benign ovarian cysts by a novel, gasless, single-incision laparoscopic technique: keyless abdominal rope-lifting surgery (KARS). Surg Endosc 27:189-198

6. GokhanDemirayak, (2017) A different technique in gasless laparoendoscopic single-site hysterectomy. J ObstetGynaecal 37(5):622-626

7. Li SH, Deng J, Huang FT, Gan XW, Cao YG (2014) Impact of gasless laparoscopy on circulation, respiration, stress response, and other complications in gynecological geriatrics. Int J Clin Exp Med 7:2877-2882

8. Srivastava A, Niranjan A (2016) Secrets of safe laparoscopic surgery: anaesthetic and surgical considerations. J Min Access Surg 6:91-94

9. Srisawat N, Kongwibulwut M, Laoveeravat P, Lumplertgul N, Chatkaew P, Saeyub P et al (2018) The role of intra operative parameters on predicting laparoscopic abdominal surgery associated acute kidney injury. BMC Nephrol 19(1):289-296

10. Takeda A, Imoto S, Mori M, Nakano T, Nakamura H (2011) Early experience with isobaric laparoendoscopic single-site surgery using a wound retractor for the management of ectopic pregnancy. Eur J Obstet Gynecol Reprod Biol 154(2):209-214

11. Takeda A, Imoto S, Nakamura H (2014) Gasless laparoendoscopic single-site surgery For management of adnexal masses during pregnancy. Eur J ObstetGynecolReprodBiol 180:28-34

12. Takeda A, Imoto S, Nakamura H (2014) Management of pediatric and adolescent adnexal masses by gasless laparoendoscopic single-site surgery. Eur J ObstetGynecolReprodBiol 181:66-71

13. Choi CH, Kim TH, Kim SH et al (2013) Surgical outcomes of a new approach to laparoscopic myomectomy: single-port and modified suture technique. J Minim Invasive Gynecol 21(4):580-585

14. Kang M, Kim J, Kim TJ et al (2020) Long-term outcomes of single-port laparoscopic myomectomy using a modified suture technique. ObstetGynecol Sci 63(2):164-172 
15. Yuk JS, Kim YA, Lee JH (2019) Hybrid robotic single-site myomectomy using the gelpoint platform. J Laparoendosc Adv Surg Tech A 29(11):1-3

16. Yuk JS, Ji HY, Kim KH, Lee JH (2015) Single-port laparoscopically assisted-transumbilical ultraminilaparotomic myomectomy (SPLA-TUM) versus single port laparoscopic myomectomy: a randomized controlled trial. Eur J Obstet Gynecol Reprod Biol 188:83-87

17. Parker WH (2018) Indications for morcellation in gynecologic surgery. Curr Opin Obstet Gynecol 30:75-80

18. Milad MP, Milad EA (2014) Laparoscopic morcellator-related complications. J Minim Invasive Gynecol 21:486-491

19. Leren V, Langebrekke A, Qvigstad E (2012) Parasitic leiomyomas after laparoscopic surgery with morcellation. Acta Obstet Gynecol Scand 91:1233-1236
20. Anupama R, Ahmad SZ, Kuriakose S, Vijaykumar DK, Pavithran K, Seethalekshmy NV (2011) Disseminated peritoneal leiomyosarcomas after laparoscopic "myomectomy" and morcellation. J Minim Invasive Gynecol 18:386-389

21. US Food and Drug Administration (2014) Laparoscopic uterine power morcellation in hysterectomy and myomectomy: FDA safety communication [Internet]. Silver Spring (MD): US Food and Drug Administration.

Publisher's Note Springer Nature remains neutral with regard to jurisdictional claims in published maps and institutional affiliations. 